\title{
Complications of the Transsphenoidal Approach to Sellar Lesions
}

\author{
Kesava Reddy, Derek Fewer and Michael West
}

\begin{abstract}
Transsphenoidal surgery is currently performed extensively for lesions of the sella turcica. The mortality and morbidity of this surgical approach are minimal, and the results satisfactory overall. Only a few studies have addressed the complications of this approach. The authors present a retrospective study of 200 transsphenoidal procedures in 196 patients over an eleven year period. There was one death due to meningitis. Major morbidity consisted of intraventricular hemorrhage in three patients, false aneurysm of the internal carotid artery in one patient and thalamic infarction in another patient. Minor morbidity details are presented. The pathogenesis of the most serious of these complications along with possible preventive measures are discussed.
\end{abstract}

RÉSUMÉ: Complications de l'approche transsphénoïdale dans les lésions de la selle turcique La chirurgie transsphénoïdale est maintenant pratiquée couramment pour les lésions de la selle turcique. La mortalité et la morbidité de cette approche chirurgicale sont minimes et les résultats sont en général satisfaisants. Peu d'études ont traité des complications de cette approche. Les auteurs présentent une étude rétrospective de 200 interventions transsphénoïdales pratiquées chez 196 patients sur une période de onze ans. Il y a eu un décès par méningite. La morbidité principale a été une hémorragie intraventriculaire chez trois patients, un faux anévrisme de la carotide interne chez un patient et un infarctus thalamique chez un autre patient. Nous présentons des détails mineurs de morbidité. Nous discutons de la pathogenèse des plus sérieuses de ces complications ainsi que des mesures préventives possibles.

Can J. Neurol. Sci. 1991; 18: 463-466

Transseptal transsphenoidal approach to lesions of the sella was introduced by Schloffer ${ }^{1}$ in 1907 . With minor modifications, this approach was used extensively in the early part of this century. $^{2-4}$ The recent resurgence in its popularity is attributable primarily to Hardy. ${ }^{5}$ This approach is currently widely used for all surgical lesions of the sella. ${ }^{5-9}$ Though the mortality and morbidity of this procedure are low, $, 5,6,8-10$ several serious complications have been described. ${ }^{11-20}$ Only three previous studies have directly addressed the complications of transsphenoidal surgery. ${ }^{12,15,20}$ Two of the studies ${ }^{12,15}$ were from large referral based teaching hospitals and one was a compilation of results of transsphenoidal surgery from an international panel of neurosurgeons with extensive experience with the transsphenoidal approach. ${ }^{20}$ In view of the relative paucity of information regarding the incidence of complications with the transsphenoidal approach in non-referral based institutions, we reviewed our experience with transsphenoidal surgery in a community based teaching centre over an eleven year period.

\section{Clinical Material}

Two hundred transphenoidal procedures were performed in 196 patients. Records of the patients operated upon from January 1978 to January 1989 at the two Manitoba teaching hos- pitals were reviewed with specific emphasis on perioperative complications. All complications occurring within one month of surgery were considered surgical unless otherwise proven. Seventy-three of these patients were male and 123 were female. The mean age was 47 years for males and 49 years for females. The presenting clinical features in these patients are shown in Table 1 , and the diagnoses in Table 2.

\section{Surgical Management}

Preoperative workup included a thorough endocrinologic evaluation, an ophthalmologic evaluation when necessary, along with computerized tomography (CT) in all patients. Angiography was performed only rarely when a vascular lesion was being considered in the differential diagnosis.

The surgical technique used was as described by Hardy, 5 using uniplanar fluoroscopy and the operating microscope. Prior to 1984 , submucosal septal dissection was carried out on both sides of the nasal septum and the septal cartilage partially excised and used as a stent in the sella. After 1984, the technique of unilateral submucosal dissection without excising the septum ${ }^{29}$ was used and a free fat graft obtained from the abdomen used to fill the empty space in the sella and the sphenoid sinus.

From the Sections of Neurosurgery, McMaster University, Hamilton (K.R.), University of Manitoba, Winnipeg (D.F., M.W.)

Received April 15, 1991. Accepted May 1, 1991

Reprint requests to: K. Reddy, M.D., Department of Surgery, 8th Floor, St. Joseph's Hospital, 50 Charleton Avenue East, Hamilton, Ontario, Canada L8N 4A6 


\section{RESULTS}

The perioperative complications are listed in Table 3. One patient died due to fulminant meningitis. Though the major morbidity rate is comparable to other series, the $1.5 \%$ incidence of intraventricular hemorrhage is higher than in other series. The incidence of other complications is not significantly different from other comparable series. $4,8,10$

\section{Discussion}

The mortality and morbidity in this series were comparable to those in other studies. ${ }^{10,15-16}$ All the reported complications of transsphenoidal surgery are listed in Table 4 . The single patient who died was an 80-year-old lady who developed meningitis three weeks postoperatively, having not shown any evidence of cerebrospinal fluid (CSF) leak in the interim. The incidence of meningitis in our series was similar to that in other series. ${ }^{8,15,22}$ One series had a higher incidence of meningitis, ${ }^{14}$ but the operative technique used was different (combined transethmoidal and transnasal transsphenoidal approach).

One case of carotid false aneurysm ${ }^{23}$ resulted from inadvertent straying off the midline. The variations in the anatomy of the sphenoid sinus and intracavernous carotid artery ${ }^{24}$ place this vessel at risk. The false aneurysm was treated in our case successfully by trapping. Biplanar fluoroscopy and the practice of placing a fine needle into the lesion prior to incising it ${ }^{25}$ could possibly have prevented this complication.

One case of thalamic infarction was seen in the immediate postoperative period (Figure 1). In this case, the consistency of the tumor was firm to hard, and pituitary rongeurs had to be used for tumor removal. The patient awoke from anaesthesia with dense right sided hemiplegia. Even after several months this patient continues to be severely disabled. The authors speculate that occlusion or disruption of one of the thalamic perforating vessels ${ }^{26}$ was the likely cause of infarction in this patient. It is suggested that if the tumor is of firm consistency, consideration be given to using $\mathrm{Co} 2$ laser $^{22}$ or other surgical approaches or treatment modalities to complete the removal of the tumor.

The incidence of intraventricular hemorrhage (IVH) is relatively high in our series, possibly related to the significant suprasellar extension of the tumors in all these cases with very close relationship to the floor of the third ventricle. Two of the three patients with this complication have improved but have been unable to return to their previous occupation. One patient remains in a vegetative state. In addition to very careful hemostasis, consideration has to be given to other surgical approaches in large vascular tumors.

The single case of transient blindness remains a perplexing problem. This 31-year-old lady was found (unexpectedly) to have an empty sella syndrome (ESS), and the sella was packed with absorbable gelatin sponge (GELFOAM, manufactured by Upjohn Company, Don Mills, Ont.) to prevent "chiasmal herniation" and methylmethacrylate (HISTOACRYL, distributed in Canada by Trihawk International Inc., Montreal) was used to seal it. The patient developed complete blindness 36 hours postoperatively. In the absence of any CT changes, empirical steroid therapy resulted in rapid improvement of vision to normalcy. The possibilities of nonspecific inflammation of the optic apparatus due to gelfoam or histoacryl have to be considered. The potential

\begin{tabular}{lr}
\hline Table 1. Presenting Clinical Features & \\
\hline \hline ENDOCRINE: & 76 \\
Amenorrhoea/Galactorrhoea/Infertility (F) & 20 \\
Acromegaly & 14 \\
Decreased Libido/Impotence (M) & 14 \\
Cushing's Disease & 4 \\
Panhypopituitarism & 2 \\
Nelson's Syndrome & 1 \\
Diabetes Insipidus & 1 \\
SIADH & \\
NEUROLOGIC: & 58 \\
Decreased Vision & 11 \\
Diplopia & 10 \\
Decreased Memory/Dementia & 3 \\
Somnolense & 2 \\
Seizures & 2 \\
Anosmia/Parosmia & 2 \\
Gait Apraxia & 1 \\
Incontinence & 1 \\
Loss of Consciousness & \\
OTHER: & 34 \\
Headache & 12 \\
Lethargy/General Malaise & 3 \\
Asymptomatic & 1 \\
Intractable Pain & \\
\hline
\end{tabular}

\begin{tabular}{lr}
\hline Table 2. Diagnoses & \\
\hline \hline Microadenoma & 63 \\
Macroadenoma & 31 \\
Confined to Sella & 71 \\
Extrasellar Extension & 8 \\
Pituitary Apoplexy & 4 \\
Empty Sella Syndrome & 3 \\
Craniopharyngioma & 3 \\
Meningioma (Biopsy) & 1 \\
Sellar Cysts & 1 \\
Diffuse Glandular Hyperplasia & 6 \\
Normal Adenohypophysis & 3 \\
Hemi/Total Hypophysectomy & 1 \\
Radiologic Microadenoma & \\
Carcinoma of Lung & \\
\hline
\end{tabular}

\begin{tabular}{lr}
\hline Table 3. Complications of the Transsphenoidal Approach \\
\hline \hline MORTALITY & 1 \\
MAJOR MORBIDITY & 1 \\
Meningitis & 1 \\
Carotid False Aneurysm & 2 \\
Intraventricular Hemorrhage & 1 \\
Thalamic Infarction & \\
MINOR MORBIDITY & 41 \\
DIABETES INSPIDUS & 1 \\
lasting less than 1 week & 1 \\
lasting less than 3 months & 8 \\
permanent & 5 \\
Transient CSF Leak & 5 \\
Septal Perforation & 4 \\
SIADH (Transient) & 2 \\
Paranasal Sinusitis & 1 \\
Urinary Tract Infection & 1 \\
Numbness Upper Lip/Tip of Nose & 1 \\
Deep Vein Thrombosis & \\
Transient Blindness & \\
Hydrocephalus &
\end{tabular}


Table 4. Reported Complications of the Transsphenoidal Approach

VASCULAR
Vascular occlusion ${ }^{16,17,20}$
False aneurysm $^{13,19,23}$
Mycotic aneurysm $^{18}$
Vasospasm $^{16,17}$
Thalamic infarction $^{\text {Subarachnoid hemorrhage }}{ }^{17}$
Hematoma $^{\text {Intrasellar }}{ }^{10}$
Intratumoral
Intracerebral
Intraventricular
Cerebral Thrombophlebitis

NASAL

Septal perforation $9,15,16$

Saddle nose deformity ${ }^{9}$

Epistaxis $^{20}$

Palatal diastasis9,15,16

Lip numbness ${ }^{9}$

DENTAL $^{32}$

Numbness

Discoloration

VISUAL (PERMANENT/TRANSIENT) 11,15-17,20,28

Decreased acuity

Visual field defects ${ }^{9,16}$

Diplopia

Oculomotor palsy $8,17,20$

Abduscens palsy ${ }^{8,17}$

\section{NEUROLOGIC}

Seizures 9

Hydrocephalus $^{8}$

Hypothalamic injury ${ }^{3,15,16,20}$

Encephalopathy ${ }^{20}$

Anosmia ${ }^{9}$

INFECTIOUS

Meningitis ${ }^{9,14-16,20}$

Sellar abscess ${ }^{20}$

Sinusitis $9,15,16$

Abdominal wound infection ${ }^{28}$

ENDOCRINE

Diabetes Insipidus ${ }^{8,12.15 .16 .20}$

Permanent

Temporary

SIADH

Hypopituitarism

\section{MISCELLANEOUS}

CSF leak ${ }^{8-9,15,16}$

Pneumocephalus ${ }^{20}$

Tension pneumocephalus ${ }^{21}$

Orbital floor fracture ${ }^{33}$

\section{SYSTEMIC}

Pulmonary embolism ${ }^{20}$

Myocardial infarction

Deep vein thrombosis

GI bleed ${ }^{20}$

Anesthetic Complications

Air embolism ${ }^{34}$

causes of visual deterioration following transsphenoidal surgery have been reviewed recently. ${ }^{11}$

The incidence of CSF leak in our series was comparable to that in other series. . $^{8,10,12,15}$ Various sellar reconstructive techniques have been described to prevent this complication. ${ }^{27}$

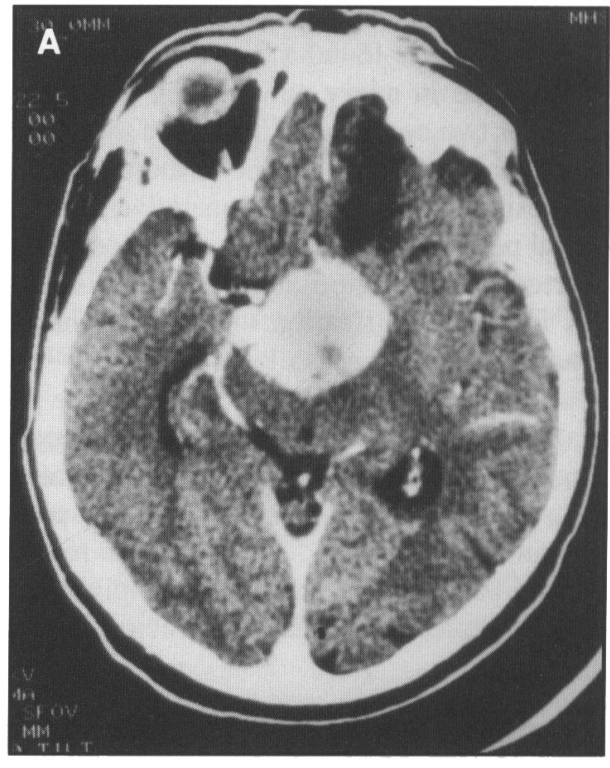

Figure $1 a-$ The preoperative $C T$ scan of a male with a non-secretory pituitary tumor (please note the left frontal hypoluscency related to the previous subfrontal resection).

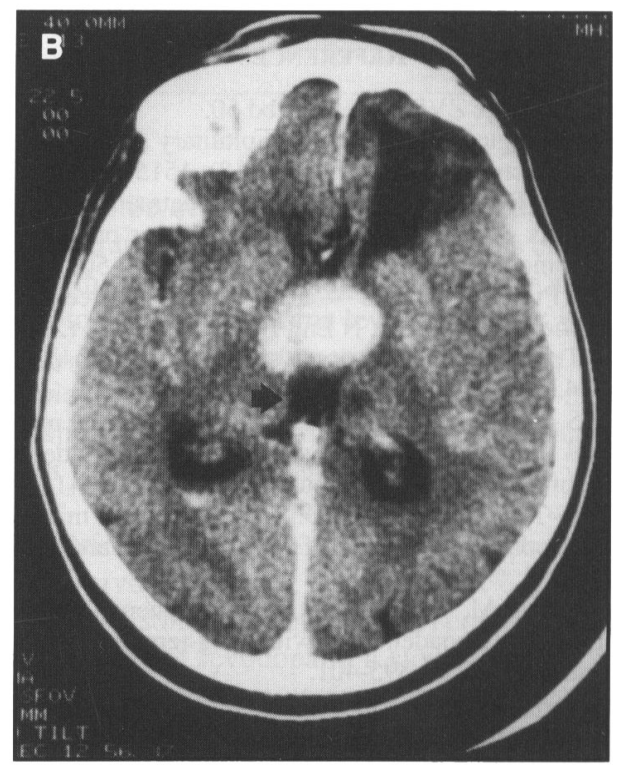

Figure $1 b-$ Post-operative $C T$ scan showing $a$ left thalamic infarction.

Detailed evaluation of endocrinologic outcome was considered to be outside the scope of this study. The incidence of permanent diabetes incipidus (DI) in our series compares favourably with others, ${ }^{12,15,16}$ though our incidence of transient DI is quite high. Most series have not considered transient early DI. ${ }^{12,15,16}$ 
The incidence of early transient DI was considered in one series of prolactinomas and was found to be $60 \% .{ }^{28}$ In our series, this diagnosis was made in every patient who passed more than $200 \mathrm{cc}$ of urine for two consecutive hours and required treatment with a possible diagnosis of DI. Some of these cases could well have been diuresis in response to intraoperative overhydration.

Of the septal perforations seen in this series, only one occurred after we started using the unilateral septal dissection technique. ${ }^{29,30} \mathrm{~A}$ further modification to preserve the entire cartillagenous and bony septum has been described, ${ }^{31}$ though we have no experience with this technique. In all these patients the nasal perforations were treated with conservative local measures with ensuing complete recovery. Most of the patients complained of upper lip numbness in the immediate postoperative period but the incidence of this complication on routine followup was found to be extremely low. The complication rate was felt to be greater in macroadenomas than microadenomas.

\section{ConClusions}

The authors conclude that the incidence of complications related to transsphenoidal surgery in this series was comparable to others, though the incidence of intraventricular hemorrhage was found to be higher. The incidence of complications appeared to increase with an increase in the size of the tumors, especially if they had significant extrasellar extension. Various precautionary measures are suggested in an effort to prevent serious complications.

\section{REFERENCES}

1. Schloffer. Beitrage ZVR Klin Chir, bd 50.

2. Cushing H. Surgical experience with pituitary disorder - The Weir Mitchell Lecture. JAMA 1914; 63 (18): 1515-1525.

3. Halstead AE. Remarks on the operative treatment of tumors of the hypophysis - with the reports of two cases operated on by an oronasal method. Surg Gyn Obs 1910; 10: 494-502.

4. Hirsch $O$. Pituitary tumors - a borderline between cranial and trans-sphenoidal surgery. N Eng J Med 1956; 254 (20): 937-939.

5. Hardy J. Transsphenoidal hypophysectomy. J Neurosurg 1971; 34: 582-594.

6. Baskin DS, Boggan JE, Wilson CB. Transsphenoidal microsurgical removal of growth hormone secreting pituitary adenomas - a review of 137 cases. J Neurosurg 1982; 56: 634-641.

7. Boggan JE, Tyrell B, Wilson CB. Transsphenoidal microsurgery of Cushing's disease - report of 100 cases. J Neurosurg 1983; 59: 195-200.

8. Ciric I, Mikhael M, Stafford T, et al. Transsphenoidal microsurgery of pituitary macroadenomas with long-term followup results. J Neurosurg 1983; 59: 395-401.

9. Kennedy DW, Cohn ES, Papel ID, et al. Transsphenoidal approach to the sella: The John Hopkins experience. Laryngoscope 1984; 94: 1066-1074.

10. Wilson CB, Dempsey LC. Transsphenoidal microsurgical removal of 250 pituitary adenomas. J Neurosurg 1978; 48: 13-22.

11. Barrow DL, Tindall GT. Loss of vision after transsphenoidal surgery. Neurosurgery 1990; 27 (1); 60-68.

12. Black PMcL, Zervas NT, Candia GL. Incidence and management of complications of transsphenoidal operations for pituitary adenomas. Neurosurgery 1987; $20(6): 920-924$.
13. Carbezudo JM, Carrillo R, Vaquero J, et al. Intracavernous aneurysm of the carotid artery following transsphenoidal surgerycase report. J Neurosurg 1981; 54: 118-121.

14. Gransden WR, Wickstead M, Eykyn S. Meningitis after transsphenoidal excision of pituitary tumors. J Laryngol Otol 1988; 102 : 33-36.

15. Laws ER, Kem EB. Complications of transsphenoidal surgery. Clin Neurosurg 1975; 23: 401-416.

16. Laws ER, Kern EB. Complications of transsphenoidal surgery. In: Tindall GT, Collins WF, eds. Clinical management of pituitary disorders. New York: Raven Press 1979; 435-445.

17. Laws ER, Trautmann JC, Hollenhurst RW Jr. Transsphenoidal decompression of the optic nerve and chiasm-visual results in 62 patients. J Neurosurg 1977; 46: 717-722.

18. Onishi $\mathrm{H}$, Ito $\mathrm{H}$, Kuroda $\mathrm{E}$, et al. Intracranial mycotic aneurysm associated with transsphenoidal surgery to the pituitary adenoma. Surg Neurol 1989; 31: 149-154.

19. Paullus WS Jr., Norwood CW, Morgan HW. False aneurysm of the cavernous carotid artery and progressive external opthalmoplegia after transsphenoidal hypophysectomy-case report. J Neurosurg 1979; 51: 707-709.

20. Zervas NT. Surgical results in pituitary adenomas: results of an international survey. In: Black P McL, Zervas NT, Ridgway EC Jr., Martin JB, eds. Secretory tumors of the pituitary gland. New York: Raven Press 1984: 377-85.

21. Shields CB, Valdes-Rodriguez AG. Tension pneumocephalus after transsphenoidal hypophysectomy - case report. Neurosurgery 1982; 11 (5): 687-689.

22. Black P McL, Zervas NT, Candia GM. Management of large pituitary adenomas by transsphenoidal surgery. Surg Neurol 1988; 29: 443-447.

23. Reddy K, Lesiuk H, West M, et al. False aneurysm of the cavernous carotid artery: A complication of transsphenoidal surgery. Surg Neurol 1990; 33: 142-145.

24. Renn WH, Rhoton AL Jr. Microsurgical anatomy of the sellar region. J Neurosurg 1975; 43: 288-298.

25. Fugii K, Chambers SM and Rhoton AL. Neurovascular relationships of the sphenoid sinus. A microsurgical study. J Neurosurg 1981; 50: 31-39.

26. Bogousslavsky J, Regli F, Uske A. Thalamic infarcts: clinical syndromes, etiology and prognosis. Neurology 1988; 38: 837-848.

27. Spaziante R, deDivitilis E, Cappabianca P. Reconstruction of the pituitary fossa in transsphenoidal surgery: an experience of 140 cases. Neurosurgery $1985 ; 17$ (3): 453-458.

28. Faria MA, Tindall GT. Transsphenoidal microsurgery for prolactinsecreting pituitary adenomas-results in 100 women with the amenorrhoea-galactorrhoea syndrome. J Neurosurg 1982; 56: 33-43.

29. Tindall GT, Collins WF, Kirchner JA. Unilateral septal technique for transsphenoidal microsurgical approach to the sella. J Neurosurg 1978; 49: 138-142.

30. Watson SW, Sinn DP, Neuwelt EA. Dental considerations in the sublabial transsphenoidal surgical approach to the pituitary gland. Neurosurgery 1982; 10 (2): 236-241.

31. Fukushima T, Sano K. Sublabial rhinoseptoplastic technique for transsphenoidal pituitary surgery by a hinge-septum methodtechnical note. J Neurosurg 1980; 52: 867-870.

32. Riche $H$, Chacomac R, Charlot $M$, et al. Pansiusitis of the face with cerebral thrombophlebitis. A rare complication of pituitary surgery. Presse Med 1987; 16 (33): 1655.

33. Newmark III H, Kant N, Duerksen R, et al. Orbital floor fracture: An unusual complication of transseptal transsphenoidal hypophysectomy. Neurosurgery 1983; 12 (5): 555-556.

34. Newfeld P, Albin MS, Chestnut JS, et al. Air embolism during transsphenoidal pituitary operations. Neurosurgery $1978 ; 2$ (1): $39-42$. 